\title{
ERRADICAÇÃO DA POBREZA: CONTRIBUIÇÕES DO PROGRAMA DE TRANSFERÊNCIA DE RENDA BOLSA FAMÍLIA PARA O CUMPRIMENTO DO ODS1 (OBJETIVO DE DESENVOLVIMENTO SUSTENTÁVEL 1) DA AGENDA 2030 DA ONU
}

\author{
Mártin Perius Haeberlin ${ }^{1}$ \\ Rodimar Silva da Silva ${ }^{2}$
}

\begin{abstract}
RESUMO: Refletir em que medida o Programa Bolsa Família(PBF) contribui para o cumprimento do ODS1, de erradicação da pobreza, da agenda 2030-ONU. A metodologia utilizada foi de pesquisa bibliográfica e análise de dados estatísticos. O estudo permitiu concluir que o PBF tem contribuído para diminuição da pobreza extrema, ainda que necessite ampliação e maior adesão da população que vive em extrema vulnerabilidade. Também foi possível apurar que as políticas públicas de inserção ao mercado de trabalho para geração de renda, além das políticas de inclusão social como garantias de direitos, precisam ser transversais e integradas ao PBF.
\end{abstract}

PALAVRAS-CHAVE: objetivo de desenvolvimento social - ODS -; pobreza; bolsa família; política pública.

\section{POVERTY ERADICATION: BOLSA FAMÍLIA PROGRAM CONTRIBUTIONS TO FULFILLMENT OF SUSTAINABLE DEVELOPMENT GOAL 1 OF UN 2030 AGENDA}

\begin{abstract}
To reflect to what extent the Bolsa Família Program (PBF) contributes to the fulfillment of the SDG1, of poverty eradication, of the 2030-UN agenda. The methodology used was bibliographic research and statistical data analysis. The study concluded that the PBF has contributed to the reduction of extreme poverty, although it needs expansion and greater adherence of the population living in extreme vulnerability. It was also possible to verify that the public policies of insertion to the labor market for income generation, besides the social inclusion policies as guarantees of rights, need to be transversal and integrated to the PBF.
\end{abstract}

KEYWORDS: social development objective - ODS -; poverty; family bag; public politics.

\section{INTRODUÇÃO}

\footnotetext{
${ }^{1}$ Doutor em Direito (PUCRS). Mestre em Direito do Estado (PUCRS). Pós-Doutorado em Economia (UFRGS), com bolsa da CAPES (Processo n. 23038.004864/2015-63). Pesquisador Visitante do Max-Planck-Institut für ausländisches öffentliches Recht und Völkerrecht. Professor da Graduação em Direito e do Mestrado em Direitos Humanos do Centro Universitário Ritter dos Reis. Advogado. E-mail: mphaeberlin@ gmail.com Lattes: http://lattes.cnpq.br/5190995351722855. ORCID: https://orcid.org/0000-0003-3101-5419

${ }^{2}$ Mestrando em Direitos Humanos pela UniRitter Laureaute International Universities, Especialização Lato Sensu em Direito do Trabalho e Previdenciário pela UniRitter. Advogado. E-mail: rodimarsilva1 @ gmail.com, Lattes: http://lattes.cnpq.br/1043857576139717, ORCID: https://orcid.org/0000-0002-7189-2339
} 
A Agenda 2030 foi adotada por centenas de países, cujos líderes presentes na sede da ONU, em Nova York (na cúpula das Nações Unidas), em setembro de 2015, pactuaram uma espécie de plano de ação sobre o Desenvolvimento Sustentável Global. A natureza dessa pactuação tem status de plataforma orientadora para a comunidade internacional e para os respectivos governos nacionais na promoção da prosperidade comum e do bem-estar para todos, a ser cumprida num prazo de 15 (quinze) anos (ONU, 2015, p. 1).

Pautada em 17 (dezessete) Objetivos de Desenvolvimento Sustentável Globais - ODS - e 169 (cento e sessenta e nove) metas, a Agenda 2030 inaugura uma era de convergência de esforços, face a constatação das mazelas mundiais que assolam as diferentes nações pactuantes.

Nos anais informativos da ONU, consta que os signatários dessa importante agenda pretendem fazê-la superar, por meio do cumprimento dos ODS,o legado dos Objetivos de Desenvolvimento do Milênio, a fim de lograrem alcançar o que esses últimos não conseguiram, em especial: concretização de direitos humanos, o alcance da igualdade de gênero, o empoderamento das mulheres e meninas, além, é claro, do primeiro e grande desafio: a superação da pobreza extrema. Nos signos da agenda, busca-se extirpar a pobreza em todas as suas formas, em todos os lugares (ONU, 2015, p. 1).

Nesse espírito audacioso e integrado que destaca historicamente essa decisão de pactuação, o Brasil não foi um mero concordante, mas um compromissado dessa importante priorização de objetivos voltados para o pleno, responsável e sustentável desenvolvimento.

Diante desse cenário, este artigo pretende analisar em que medida o Programa de Transferência de Renda Bolsa Família contribui para o cumprimento do ODS1(Objetivo de Desenvolvimento Sustentável 1) de erradicação da pobreza. A metodologia utilizada foi a da pesquisa bibliográfica e análise de dados estatísticos, a partir de resultados descritos.

Nessa perspectiva analítica, lançar mão de indicadores sociais permite visualizar a fotografia da gênese social atual do Brasil, de modo a observar o impacto de programas como o Bolsa Família e outros, como políticas de inserção ao mercado de trabalho, na diminuição da pobreza extrema bem como na geração de emprego e renda.

\section{ERRADICAÇÃO DA POBREZA - ODS 1 DA AGENDA 2030 DA ONU}

A Agenda 2030, em seu Objetivo de Desenvolvimento Sustentável 1 (ODS 1), tem a pretensão de acabar com a pobreza em todas as suas formas, em todos os lugares, 
consignando que 836 milhões de pessoas no mundo vivem em extrema pobreza. É portanto "um plano de ações para pessoas, para o planeta e para a prosperidade" (ONU, 2015, p. 1), estimulando as ações dos países na busca pelo desenvolvimento sustentável.

Esse objetivo refere-se à pobreza em relação ao ponto de vista econômico, definindo metas para garantir um grau de empoderamento financeiro que permita acesso aos meios necessários para manutenção da vida e a redução das vulnerabilidades.

O documento que institui os Objetivos de Desenvolvimento Sustentável tem grande destaque no âmbito social, evidenciando, assim, a erradicação da extrema pobreza como o principal desafio global, e como um dos pontos mais sensíveis e importantes para o desenvolvimento e a redução das desigualdades sociais. (FURTADO, 2018, p. 4).

O objetivo número 1 elenca cinco metas para seu cumprimento, que vão desde, erradicar a pobreza extrema para todas as pessoas em todos os lugares até criar marcos políticos sólidos, em nível nacional, regional e internacional, com base em estratégias de desenvolvimento a favor dos pobres e sensíveis a gênero.

Conforme dados da ONU, vivendo na pobreza na América Latina e Caribe, o que inclui estatísticas referentes ao Brasil, havia 184 milhões de pessoas em 2017 (30,2\% da população), com estimativa de pequena melhora em 2018, mesmo assim atingindo o patamar de 182 milhões de pessoas. Já a pobreza extrema atingia 10,2\% da população em 2017, cerca de 62 milhões de pessoas; e as estimativas para 2018 eram de aumento para 63 milhões (CEPAL, 2017).

No Brasil, conforme Síntese de Indicadores Sociais - SIS - (AGENDA IBGE NOTÍCIAS, 2018), divulgada em dezembro/2018, que analisou o tema da pobreza, constatouse um aumento dessa mazela entre 2016 e 2017, pois conforme a linha de pobreza proposta pelo Banco Mundial (rendimento de até US\$ 5,5 por dia, ou R \$ 406 por mês), a proporção de pessoas pobres era de 25,7\% da população em 2016 e subiu para 26,5\%, em 2017. Em números absolutos, esse contingente variou de 52,8 milhões para 54,8 milhões de pessoas no período. Nessa mesma análise, a proporção de crianças e adolescentes de 0 a 14 anos que viviam com rendimentos de até US\$ 5,5 por dia passou de $42,9 \%$ para $43,4 \%$ no mesmo período.

No tocante às pessoas com renda inferior a US\$ 1,90 por dia (R \$ 140 por mês), que estariam na extrema pobreza de acordo com a linha proposta pelo Banco Mundial, essa faixa representava $6,6 \%$ da população do país em 2016, comparado com 7,4\% em 2017. Em 
números absolutos, constatou-se aumento de 13,5 milhões em 2016 para 15,2 milhões de pessoas em 2017.

Nessa toada, ainda que em 2015 não houvesse sido mensurado os indicadores antes elencados, o comprometimento do Brasil, enquanto estado-nação, com o ODS1 efetivamente é uma política pública relevante, do ponto de vista de importância de pauta.

A concordância da adoção dos ODS construídos na Agenda 2030, especialmente do primeiro deles, aliada ao objetivo fundamental da República Federativa do Brasil, contido no art. $3^{\circ}$, inciso III, da Constituição Federal, representam verdadeiro avanço em termos de agenda de prioridades.

Art. $3^{\circ}$ Constituem objetivos fundamentais da República Federativa do Brasil:

III - erradicar a pobreza e a marginalização e reduzir as desigualdades sociais e regionais; $(. .$.

A proeminência do ODS1 também se fundamenta, porque os sistemas sociais são diversos e têm suas diferenciações pela inclusão e exclusão, de modo que a temática da exterminação da pobreza extrema, como forma de equação das desigualdades sociais e defesa de direitos humanos, não é matéria exclusiva do sistema político, porque intersecciona-se com outros sistemas de modo a justificar a necessidade de atuação efetiva do Estado (BACHUR, 2012, p. 61).

A inclusão e exclusão são pressupostos operativos, que funcionam como condições lógicas para que os sistemas sociais operem estruturalmente acoplados uns aos outros. Ou seja, cada um com suas diferenciações, mas permitindo acoplarem-se para produzirem resultados úteis capazes de minimizar ou combater o mal gerado pela própria sociedade devastadora capitalista (BACHUR, 2012, p. 61)

Justifica-se a necessidade de atuação do Brasil, em suas diversas esferas, para deflagrar força-tarefa de combate e extirpação à extrema pobreza. Combate, porque trata-se de enfermidade social que fere frontalmente a dignidade humana extirpação, porque a solução de continuidade é medida imperiosa.

A extrema pobreza foi pautada como sendo o primeiro dos objetivos de desenvolvimento sustentável, pelos alarmantes números que exprime, com efeito, milhares de pessoas sobrevivem de modo degradante, sem condições mínimas de moradia, saneamento e alimentação. 
Os dados colhidos pelo IBGE, via Síntese de Indicadores Sociais, traz à tona, claramente, a realidade brasileira, em que, por exemplo, mulheres pretas ou pardas são o grupo mais vulnerável, pois dentre os 7,6 milhões de moradores de domicílios onde vivem tais mulheres - sem cônjuge com filhos até 14 anos - 64,4\% estava abaixo da faixa de renda de até $\mathrm{R} \$$ 406,00 mensais.

O quadro abaixo colacionado dimensiona os números e percentuais acima referidos:

\section{Proporção de pessoas abaixo da linha de pobreza}

Por arranjo domiciliar no Brasil - 2017

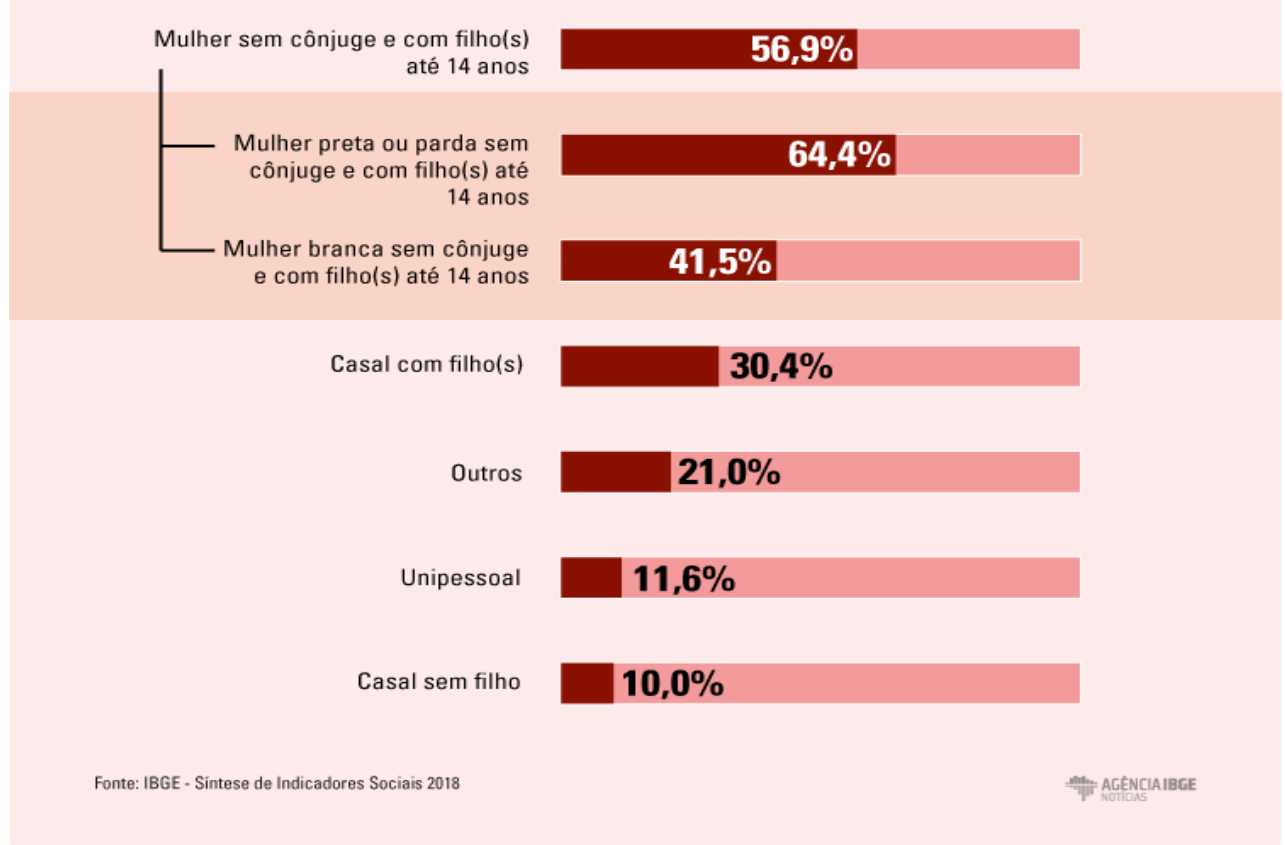

Reside, portanto, a temática do combate ou exterminação da extrema pobreza em sistemas sociais distintos, que pela interconectividade, devem responder a tal demanda harmoniosamente, sem que com isso haja irritação de um ou outro complexo.

Os indivíduos alvo de proteção, in casu, destinatários finais do ODS1, portanto, devem ser incluídos em todos os sistemas, cuja diferenciação funcional de cada um deve servir para concretude do objetivo. Exemplificando: no sistema político, as políticas públicas; na sociedade, as organizações da sociedade civil, com seus projetos sociais; na iniciativa privada, com oportunidades dignas de trabalho e oferecimento de qualificação (BACHUR, 2012, p. 59). 
As funcionalidades dos sistemas sociais devem garantir a cidadania integral dos indivíduos. A participação plena na sociedade e a fruição com dignidade, sem o achaque da miserabilidade, são exemplos dessas funcionalidades nas dimensões política, civil e social, em termos de direitos (BACHUR, 2012, p. 59).

Mas, para que os indivíduos possam desfrutar dessa participação cidadã, devem estar respaldados de condições a fim de desenvolverem capacidades ao ponto de superarem a mazela da pobreza (SEN,1999, p. 101-102).

Nesse sentido, segundo Amartya Sen (1999, p. 101-102), entender o que realmente significa pobreza, não apenas como escassez de renda, cuja inadequação é frequentemente a principal causa de privações é necessário.

A pobreza, portanto, pode ser definida como um mundo complexo e a descoberta de todas as suas dimensões exige uma análise clara, não se podendo estabelecer uma linha e aplicá-la rigidamente a todos da mesma forma, sem levar em conta as características e circunstâncias pessoais de cada indivíduo. Certos fatores geográficos, biológicos e sociais multiplicam ou reduzem o impacto exercido pelos rendimentos sobre cada indivíduo. Entre os mais desfavorecidos faltam em geral determinados elementos, como instrução, acesso à terra, saúde e longevidade, justiça, apoio familiar e comunitário, crédito e outros recursos produtivos, voz ativa nas instituições e acesso a oportunidades (SEN, 1999, p. 102).

Ser pobre, para Sen (1999, p. 102), não significa viver abaixo de uma linha imaginária de pobreza - por exemplo, auferir um rendimento igual ou inferior a US\$2 por dia. Ser pobre é ter um nível de rendimento insuficiente para desenvolver determinadas funções básicas, levando em conta as circunstâncias e requisitos sociais circundantes, sem esquecer a interconexão de muitos fatores.

É por isso que o autor (1999, p. 102-103) também afirma que a capacidade de uma pessoa consiste nas combinações alternativas de funcionamentos cuja realização é factível para ela, de modo que a pobreza é a impossibilidade de uma pessoa, ou grupo de pessoas, transformar essas capacidades em oportunidades para viverem a vida de acordo com seus objetivos e vontades, ou ainda, a incapacidade de alcançar o bem-estar devido à falta de meios econômicos e à impossibilidade de converter rendimentos e recursos escassos em capacidade de funcionar.

Extrema pobreza, nesse sentido, é uma mazela cujo mal invalida indivíduos, subtraindo-lhes capacidades. Para Sen (1999, p. 118) a retirada das capacidades dos 
indivíduos, haja vista os fatores externos e até alheios à sua vontade, implica na restrição das liberdades substantivas, ou, em outras palavras, de fazerem coisas que eles têm razão para prezar e para levarem o tipo de vida que valorizam.

Assim, em termos de Direitos Humanos, não há como não conceber que a superação da miséria absoluta é objeto de alçada jurídica, social, econômica e política. Daí a afirmação de "[...] ninguém escolhe o berço onde nasce, é a sociedade que deve se responsabilizar pelas classes que foram esquecidas e abandonadas." (SOUZA, 2017, p. 118)

Neste ínterim, o compromisso do ODS1 em relação ao Brasil, no caso do presente artigo, pode se dar por meio do Programa de Transferência de Renda Bolsa Família, como uma política pública de relevante papel na estruturação de combate à vulnerabilidade social extrema.

\section{PROGRAMA DE TRANSFERÊNCIA DE RENDA BOLSA FAMÍLIA}

O Programa Bolsa Família (PBF) instituído pela Lei n. 10.836, de 9 de janeiro de 2004 e regulamentado pelo Decreto n. 5.209, de 17 de setembro de 2004, é uma política de transferência de renda direta destinada às famílias em vulnerabilidade social, desde que atendidas determinadas condicionalidades.

As condicionalidades do PBF são nas áreas de saúde, educação e assistência social: calendário vacinal; o crescimento e desenvolvimento de crianças menores de sete anos; exame pré-natal para gestantes e o acompanhamento de nutrizes em atividades de educação em saúde e nutrição; frequência escolar mínima de $85 \%$ da carga horária mensal para crianças e adolescentes de 6 a 15 anos de idade; frequência escolar mínima de 75\% da carga horária mensal para adolescentes de 16 e 17 anos; frequência mínima de 85\% da carga horária relativa aos serviços socioeducativos e de convivência do Programa de Erradicação do Trabalho Infantil para crianças e adolescentes menores de 16 anos. (MDS, 2015).

O Programa Bolsa Família integra estratégia governamental de combate a fome e a pobreza, promover a segurança alimentar e nutricional e o acesso aos serviços públicos e estimular o desenvolvimento socioeconômico do país, atuando em três dimensões essenciais: alívio imediato da pobreza por meio de transferência direta de renda às famílias; exercício dos direitos sociais básicos nos setores de educação, saúde e assistência social, através do cumprimento das condicionalidades; e, capacitação das famílias através de programas complementares de alfabetização, de geração de emprego e renda, entre outros (MDS, 2015). 
Desde a instituição do PBF ocorreram mudanças na legislação como atualizações nos valores da renda de transferências, ampliação do público e alterações de procedimentos e gestão, na perspectiva de melhores resultados.

$\mathrm{O} \mathrm{PBF}$ é reconhecido pela $\mathrm{ONU}$ como um programa de sucesso ao combate à pobreza, permitindo ao Brasil cumprir gradativamente o ODS 1 da Agenda 2030 de 2015, pois integra uma política pública de intervenção direta, por abranger o conceito de pobreza pela renda e transferir renda diretamente àquelas famílias em situação de pobreza e extrema pobreza e por incluir condicionantes nas dimensões de qualidade de vida: educação, saúde e assistência social (MDS, 2015).

Nessa perspectiva, o PBF atende os preceitos do desenvolvimento humano, pois inclui no escopo do programa dimensões que atendem as necessidades básicas da população em condição de vulnerabilidade socioeconômica (REGO \& PINZANI, 2014, p. 237).

Além disso, é a transferência de renda pública que mais alcança a população pobre no Brasil, uma vez que cerca de $70 \%$ dos recursos do programa alcançaram os $20 \%$ mais pobres, reduzindo a pobreza em $15 \%$ e a extrema pobreza em $25 \%$, conforme pesquisa do Instituto de Pesquisa Econômica Aplicada, a qual analisou "Os efeitos do Programa Bolsa Família (PBF) sobre a pobreza e a desigualdade: Um balanço dos primeiros 15 anos" (IPEA, 2019).

Partindo dessa mesma pesquisa, apurou-se que o PBF também responde por $10 \%$ de redução da desigualdade no Brasil, entre 2001 e 2015. Tal dado mostra a relevância do impacto, especialmente se considerado o baixo custo do programa, de apenas $0,5 \%$ do Produto Interno Bruto (PIB) (IPEA, 2019).

Essa análise dos impactos gerados pelo programa de transferência de renda feita pelo Ipea foi baseada em dados da Pesquisa Anual por Amostra de Domicílios (Pnad), de 2001 a 2017, do Instituto Brasileiro de Geografia e Estatística.

O Programa Bolsa Família beneficiou, no mês de agosto de 2019, 13.826.716 famílias, que receberam benefícios com valor médio de $\mathrm{R} \$ 188,63$. O valor total transferido pelo governo federal em benefícios às famílias atendidas alcançou $\mathrm{R}$ \$ 2.608.191.765,00 no mês (APLICAÇÕES MDS, 2019).

Em relação às condicionalidades, o acompanhamento da frequência escolar, com base no bimestre de março de 2019, atingiu o percentual de 94,0\%, para crianças e adolescentes entre 6 e 15 anos, o que equivale a 286.205 alunos acompanhados em relação ao público no perfil equivalente a 304.395. Para os jovens entre 16 e 17 anos, o percentual atingido foi de 
87,9\%, resultando em 44.927 jovens acompanhados de um total de 51.128. Já o acompanhamento da saúde das pessoas (crianças até 7 anos e mulheres de 14 a 44 anos), na vigência de dezembro de 2018, atingiu 73,5\%, percentual equivale a 460.132 pessoas de um total de 626.108 que compunham o público no perfil para acompanhamento da área de saúde do estado (APLICAÇÕES MDS, 2019).

Os percentuais e números obtidos por essas pesquisas reforçam que as políticas sociais implementadas no Brasil, especialmente para o recorte do caso em tela (PBF), têm assegurado provisão mínima social, de modo a objetivamente promover proteção social à família, à maternidade, à infância, à adolescência, à velhice, como direito do cidadão e dever do Estado, integrando ações de iniciativa pública e da sociedade, especialmente de enfrentamento da pobreza, nos termos do texto constitucional e da LOAS - Lei Orgânica da Assistência Social (Lei Federal 8.742/1993).

Nessa perspectiva, os dados acima citados, em relação ao impacto do Programa Bolsa Família permite se “...pensar que possui em germe condições de se transformar em política pública de cidadania, assim efetivando no Brasil um desenvolvimento não somente econômico, mas também democrático, diversamente do ocorrido nas décadas de 1930 a 1970” (REGO \& PINZANI, 2014, pág. 218).

Inclusive Lício (IPEA, 2451, 2019), afirma que:

No Bolsa Família, o que se busca integrar é a oferta de serviços universais de saúde, educação e assistência social, com foco especial no público-alvo do programa, considerando suas dificuldades estruturais para acessar estes serviços por meio da oferta regular. Essas políticas são formuladas e cofinanciadas pelos três níveis de governo, mas executadas pelos municípios, a partir de pactos, protocolos, capacitação, sistemas de informação e procedimentos definidos nacionalmente, inclusive no que diz respeito ao público do PBF, e contam com uma concepção minimamente comum quanto ao propósito das condicionalidades em relação aos seus objetivos setoriais.

Portanto, o Programa Bolsa Família (PBF) é uma das principais iniciativas brasileiras no combate à extrema pobreza, não apenas pelo benefício pago às famílias pobres, mas também por promover sua priorização pelas políticas de saúde, educação e assistência social.

A propósito, segue abaixo, quadro comparativo em relação às famílias beneficiadas pelo PBF nos anos 2004, 2010 e 2014, demonstrando evolução e maior abrangência. 
Tabela: Famílias beneficiárias e valores repassados pelo Programa Bolsa Família

\begin{tabular}{|c|c|c|c|c|c|c|c|}
\hline ESTADO & $\begin{array}{c}\text { Estimativa } \\
\text { de } \\
\text { famílias } \\
\text { pobres - } \\
\text { Perfil } \\
\text { Bolsa } \\
\text { Família } \\
\text { (CENSO } \\
\text { 2010) }\end{array}$ & $\begin{array}{c}\text { Bolsa } \\
\text { Família - } \\
\text { Famílias } \\
\text { Beneficiárias } \\
\text { (2004) }\end{array}$ & $\begin{array}{c}\text { Bolsa } \\
\text { Família - } \\
\text { Famílias } \\
\text { Beneficiárias } \\
\text { (2010) }\end{array}$ & $\begin{array}{c}\text { Bolsa } \\
\text { Família - } \\
\text { Valor Total } \\
\text { Repassado } \\
\text { no período B } \\
\text { de } 2004 \text { - } \\
2010\end{array}$ & $\begin{array}{c}\text { Bolsa } \\
\text { Família - } \\
\text { Famílias } \\
\text { Beneficiárias } \\
\text { (2014) }\end{array}$ & $\begin{array}{c}\text { Bolsa } \\
\text { Família - } \\
\text { Valor Total } \\
\text { sepassado } \\
\text { (2014) }\end{array}$ & $\begin{array}{c}\text { Bolsa } \\
\text { Família - } \\
\text { Valor Total } \\
\text { Repassado } \\
\text { no período } \\
\text { de } 2004 \text { - } \\
2014\end{array}$ \\
\hline Acre & 75.893 & 28.851 & 59.779 & 340.669 .594 & 78.561 & 211.937 .759 & 949.977 .501 \\
\hline Alagoas & 392.624 & 26 & 414 & 77.803 & & .605 & 34.904 \\
\hline Amapá & 55.243 & 10.256 & 44.096 & 218.218 .429 & 55.527 & 125.823 .850 & 633.614 .501 \\
\hline Amazonas & 330.501 & 104.135 & 278.893 & 1.421 .151 .218 & 358.516 & 838.659 .333 & 4.030 .394 .793 \\
\hline Bahia & 1.659 .504 & 838.963 & 1.662 .069 & 8.520 .112 .023 & 1.808 .376 & 3.521 .434 .489 & $\begin{array}{c}20.306 .278 .36 \\
4\end{array}$ \\
\hline Ceará & 1.017 .536 & 572.730 & 1.022 .259 & 5.393.878.314 & 1.089 .813 & 2.119 .820 .489 & $\begin{array}{c}12.563 .836 .80 \\
4\end{array}$ \\
\hline $\begin{array}{l}\text { Distrito } \\
\text { Federal }\end{array}$ & 95.674 & 41.943 & 98.552 & 359.024 .506 & 86.524 & 147.613 .782 & 860.168 .802 \\
\hline $\begin{array}{l}\text { Espírito } \\
\text { Santo }\end{array}$ & 211.938 & 120.911 & 189.983 & 954.268 .679 & 190.049 & 333.798 .747 & 2.133 .571 .409 \\
\hline Goiás & 332.275 & 135.758 & 326.084 & 1.327 .436 .079 & 336.606 & 594.572 .492 & 3.401 .391 .429 \\
\hline Maranhão & 859.489 & 380.742 & 871.297 & 4.685 .458 .998 & 985.136 & 2.176.773.672 & $\begin{array}{c}11.707 .216 .24 \\
0\end{array}$ \\
\hline $\begin{array}{c}\text { Mato } \\
\text { Grosso }\end{array}$ & 185.137 & 82.116 & 167.693 & 725.960 .673 & 186.272 & 339.085 .825 & 1.862 .402 .589 \\
\hline $\begin{array}{c}\text { Mato } \\
\text { Grosso do } \\
\text { Sul }\end{array}$ & 138.382 & 32.588 & 132.887 & 568.914 .174 & 145.224 & 3.441 & 1.474 .826 .762 \\
\hline $\begin{array}{l}\text { Minas } \\
\text { Gerais }\end{array}$ & 1.190 .155 & 756.335 & 1.135 .715 & 5.756 .922 .408 & 1.143 .020 & 2.086 .335 .876 & $\begin{array}{c}12.995 .159 .17 \\
0\end{array}$ \\
\hline Pará & 828.999 & 259.641 & 6 & 426.957 .238 & 88 & .071 & 9.422 .716 .056 \\
\hline Paraíba & 451.388 & 3.135 & 450.525 & 503.459 .413 & 524.967 & 1.061 .119 .422 & 5.913 .242 .167 \\
\hline Paraná & 456.024 & 308.754 & 466.607 & 2.180 .658 .035 & 406.918 & 697.127 .973 & 4.740 .512 .245 \\
\hline $\begin{array}{c}\text { Pernambuc } \\
0\end{array}$ & 1.019 .901 & 518.956 & 1.045 .268 & 5.274 .015 .816 & 1.150 .879 & 2.170 .678 .175 & $\begin{array}{c}12.638 .734 .16 \\
0\end{array}$ \\
\hline Piauí & 397.268 & 217.931 & 420.392 & 2.250 .694 .582 & 456.811 & 989.972 .080 & 5.444 .501 .358 \\
\hline $\begin{array}{l}\text { Rio de } \\
\text { Janeiro }\end{array}$ & 897.094 & 196.330 & 685.301 & 2.724 .930 .094 & 827.847 & 1.549 .328 .023 & 7.752 .098 .943 \\
\hline $\begin{array}{l}\text { Rio Grande } \\
\text { do Norte }\end{array}$ & 329.176 & 190.116 & 338.424 & 1.738 .285 .668 & 362.805 & 693.467 .871 & 4.060 .355 .071 \\
\hline $\begin{array}{l}\text { Rio Grande } \\
\text { do Sul }\end{array}$ & 461.062 & 290.660 & 453.761 & 2.259.678.922 & 434.715 & 793.729 .853 & 5.062 .531 .344 \\
\hline Rondônia & 116.957 & 4.942 & 112 & 1.119 & 11 & 862.805 & 1.305 .756 .156 \\
\hline Roraima & 41.944 & 14.522 & 42.213 & 212.179 .610 & 48.104 & 102.887 .180 & 558.843 .604 \\
\hline $\begin{array}{c}\text { Santa } \\
\text { Catarina }\end{array}$ & 171.434 & 101.247 & 143.700 & 713.544 .987 & 137.970 & 248.631 .365 & 1.589 .746 .541 \\
\hline São Paulo & 1.651 .570 & 657.099 & 1.174 .844 & 5.406 .437 .111 & 1.327 .024 & 2.334 .973 .894 & $\begin{array}{c}13.123 .855 .30 \\
0\end{array}$ \\
\hline Sergipe & 239.382 & 113.147 & 230.418 & 1.169 .006 .324 & 281.231 & 10.850 & 2.894 .893 .609 \\
\hline Tocantins & 131.865 & 55.305 & 128.432 & 608.286 .751 & 139.295 & 281.369 .311 & 1.542 .183 .674 \\
\hline
\end{tabular}

Fonte: Ministério do Desenvolvimento Social e Combate à Fome (MDS)

(http://aplicacoes.mds.gov.br/sagi-data/misocial/tabelas/mi_social.php).

No próximo quadro colacionado, extraído dos relatórios do MDS, com recorte para o estado do Rio Grande do Sul, há demonstração do total de famílias, indivíduos (crianças, adolescentes, jovens e adultos) que constam no CadÚnico, bem como, que são beneficiários 
do PBF, cujas condicionalidades comprovam efetivo acesso a outras políticas transversais e intersetoriais, promovendo assim a inclusão social:

\section{Bolsa Família e Cadastro Único no seu Estado - Resumido Ministério da Cidadania - Secretaria Nacional de Renda e Cidadania}

População (CENSO 2010): 10.693.929 habitantes Famílias inseridas no Cadastro Único: 975.613 famílias Famílias beneficiárias do PBF: 349.255 famílias

$\%$ da população beneficiada pelo PBF: $7,95 \%$ aproximadamente

Valor transferido no mês de agosto de 2019 aos beneficiários: $\mathrm{R} \$ 60.327 .722,00$

Valor médio do beneficio: $\mathrm{R} \$ 172,73$ por família

\section{Gestão das condicionalidades}

Perfil Educação:

Total de crianças e adolescentes com perfil de educação no estado: 355.523

Total de crianças e jovens acompanhados: 331.132

Taxa de Acompanhamento de Frequência Escolar (TAFE): 93,13\%

TAFE Nacional: 90,30\%

Perfil Saúde:

Total de beneficiários(as) com perfil de saúde no estado: 626.108

Beneficiários(as) acompanhados(as): 460.132

Taxa de Acompanhamento de Agenda de Saúde (TAAS): 73,49\%

TAAS Nacional: $75,55 \%$

\section{Gestão do Cadastro Único}

Famílias com renda até $1 / 2$ salário mínimo no estado: 683.223 famílias

Famílias com renda até $1 \frac{1}{2}$ salário mínimo com o cadastro atualizada: 566.676 famílias

Taxa de Atualização Cadastral (TAC): 84,78\%

TAC Nacional: $84,91 \%$

Índice de Gestão Descentralizada (IGD):

Índice IGD do estado: 0,83 (valor máximo 1)

Último repasse (junho de 2019) realizado ao estado: $\mathrm{R} \$ 14.498,49$

Teto de repasse (mês): $\mathrm{R} \$ 69.879,00$

(Gerado em 02/09/2019)

Extraído do site https://aplicacoes.mds.gov.br/sagirmps/bolsafamilia/relatorio-resumido-estadual.html

Oportuno registrar que o IPEA em 2017, inclusive lançou um trabalho que subsidiou o primeiro Relatório Nacional Voluntário sobre os Objetivos de Desenvolvimento Sustentável (ODS), apresentado pelo Brasil no Fórum Político de Alto Nível das Nações Unidas sobre Desenvolvimento Sustentável (HLPF) de 2017, o qual entre as várias análises, gráficos e mapas, traz uma reflexão sobre os desafios a serem superados para cumprimento do ODS1:

[...] o pressuposto básico para que o país retome a desejada trajetória de erradicação da pobreza, conforme estabelecem as metas do ODS 1, passa pela articulação entre as medidas políticas macro e 
microeconômicas que induzam a volta do crescimento econômico com a necessária manutenção de patamares adequados de financiamento das políticas sociais. A combinação desses dois conjuntos de medidas é fundamental, pois o agravamento da crise econômica e do desemprego potencializa o aumento da demanda por benefícios e serviços públicos, com impactos prováveis sobre as políticas sociais, sobretudo as de assistência social.

Portanto, as declarações políticas de comprometimento com a Agenda 2030, especialmente com o ODS1, devem ser reverberadas por ações práticas intersetoriais e transdisciplinares, como pauta urgente e prioritária, mediante uma efetiva conduta de Estado de maestria e responsabilidade para com a temática, sob pena de ser apenas mais um “objetivo" sem solução de continuidade.

Aliás, Neves (2005, p. 5) tratando sobre a força simbólica dos Direitos Humanos, afirma que:

[...] a referência simbólica a determinado instituo jurídico caracterizado por um alto grau de ineficácia normativo-jurídica serve tanto ao encobrimento dessa realidade e mesmo à manipulação política para usos contrários à concretização e efetivação das respectivas normas, quanto a uma ampla realização do modelo normativo no futuro.

Embora tenha assim se manifestado (2005, p. 12), contextualizando a questão normativa dos direitos, a análise serve para o ora manifestado no tocante à necessidade de implementação de ações de enfrentamento da pobreza extrema além do PBF.

Nesse sentido, não se pode negar que a falta de condições mínimas de sobrevivência para uma parcela razoável da população - inserida naqueles dados de extrema pobreza - é uma violação "gritante e escandalosa" de direitos humanos, especialmente no que diz com à dignidade humana (NEVES, 2005, p. 12).

Desta forma, o Programa Bolsa Família é uma estratégia legítima e essencial para o combate à extrema pobreza, como forma de cumprimento do ODS1 da Agenda 2030 da ONU, em que pese não deva ser o único instrumental para tal missão.

\section{CONSIDERAÇÕES FINAIS}

O Programa Bolsa Família contribuiu no Brasil, para cumprimento da meta de redução da pobreza em todos os estados da federação. A transferência de renda diretamente para os 
beneficiários, conforme dados estatísticos analisados no presente artigo, demonstram a colaboração impactante do PBS para a redução da desigualdade de renda, e as condicionantes acompanhadas pelo referido programa permitiram a evolução do índice de desenvolvimento humano.

Os resultados efetivamente são positivos e, até certo ponto animadores, embora ainda seja necessário ampliar o alcance do PBF, mediante maior adesão de famílias e indivíduos em situação de vulnerabilidade extrema.

A meta da erradicação da pobreza até 2030, conforme ODS1, é alcançável, e o PBF não deve ser apenas tido como um programa temporal, mas sim, transformado para uma política efetiva de redução da desigualdade social, como forma equitativa de combate à extrema pobreza.

Considerando que o Brasil é um país com dimensões continentais, com uma diversidade geográfica e cultural muito grande que amplia as desigualdades regionais, o PBF traduz-se como uma iniciativa que, integrada com outras de igual importância, podem contribuir gradativamente, como visto, para a redução dessas desigualdades de renda, saúde, educação, de condição de vida e oportunidades.

Neste cenário, por ser um programa socioeconômico, o Bolsa Família agrega elevação no índice de desenvolvimento humano ao permitir que as pessoas que o acessam possam reaver sua capacidade de liberdade de escolha, mínima que seja.

Porém só o PBF não é suficiente, nem sustentável, para garantir o desenvolvimento humano em todas as suas dimensões; para isso, as políticas públicas de inserção ao mercado de trabalho para geração de emprego e renda e as políticas de inclusão social e garantias dos direitos precisam ser transversais e integradas a este.

Ao consignar-se assertiva, a Agenda 2030 da ONU por meio de seus ODS, especialmente o ODS1, há que ser o norte balizador para a elaboração dessas políticas por retratarem as preocupações globais com aplicação local e permearem por todas as dimensões do desenvolvimento humano e sustentável.

Considerando que a meta é erradicar a pobreza em todas as suas formas e lugares até 2030, que a pobreza tem uma natureza multifacetada e que o Brasil possui uma grande diversidade regional com diferentes vulnerabilidades sociais no meio rural e urbano, então a proposta de combate à pobreza há que abordar o multidimensionamento da vulnerabilidade social de cada grupo populacional para ampliar a sua efetividade. 
Nesse sentido, o PBF não deve ser o único instrumental de governança para cumprimento do ODS1, embora, como já mencionado, bastante positivo, avanços no aspecto social devem ser alavancados e levados a efeito, até porque conforme já mencionado por Santos (2013, p. 42) "[...] a grande maioria da população mundial não é sujeito de direitos humanos. É objeto de discurso de direitos humanos".

Portanto, o PBF além de outras medidas considerando os Direitos Humanos revela-se política pública claramente transversal e tangível a diferentes sistemas, pois ainda que estes permaneçam fechados, em sua essência de diferenciação, os acoplamentos estruturais podem ocorrer na sociedade moderna, de modo a permitir um resultado útil e efetivo ao destinatário de proteção. 


\section{REFERÊNCIAS BIBLIOGRÁFICAS}

BACHUR, João Paulo. Inclusão e Exclusão na teoria de sistemas sociais: um balanço crítico. BIB, São Paulo, $n^{\circ} 73,1^{\circ}$ semestre de 2012, p.55-83

CEPAL. Comunicados: disponível em https://www.cepal.org/es/comunicados/lapobrezaamerica-latina-se-mantuvo-estable-2017-pero-aumento-la-pobreza-extrema. Acesso em: 02/09/2019.

FURTADO, Nayara F. A Agenda 2030 e a redução de desigualdades no Brasil. Análise da meta 10.2. Brasília, DF. 2018. Disponível em:

http://repositorio.enap.gov.br/bitstream/1/3529/1/Nayara\%20Frutuoso\%20Furtado.pdf.

Acesso em: 02/09/2019.

GRAU, Eros Roberto. O Direito Posto e o Direito Pressuposto. $3^{\text {a }}$ ed. São Paulo: Malheiros, 2000 .

IBGE. Agencia de notícias. Disponível em https://agenciadenoticias.ibge.gov.br/agencia-salade-imprensa/2013-agencia-de-noticias/releases/23298-sintese-de-indicadores-sociaisindicadores-apontam-aumento-da-pobreza-entre-2016-e-2017. Acesso em: 02/09/2019.

IBGE. Agencia de notícias. Disponível em https://agenciadenoticias.ibge.gov.br/agencianoticias/2012-agencia-de-noticias/noticias/23299-pobreza-aumenta-e-atinge-54-8-milhoes-depessoas-em-2017. Acesso em: 02/09/2019.

IPEA. Portal. Disponível em

http://www.ipea.gov.br/portal/index.php?option=com_content $\&$ view=article \&id=34949\&cati $\mathrm{d}=10 \&$ Itemid=9. Acesso em: 02/09/2019.

IPEA. Relatório Institucional. Disponível em

http://www.ipea.gov.br/portal/images/stories/PDFs/relatorio_institucional/180308_ODS_errad icacao_da_pobreza.pdf . Acesso em: 02/09/2019.

JANNUZZI, Paulo de Martino. Indicadores sociais no Brasil: conceitos, fontes de dados e aplicações. Campinas, SP: Alínea, 2012.

LENZI, Cristiano Luís. Democracia, justiça e cultura política da sustentabilidade. 2010. Disponível em: <http://portal.mec.gov.br/seb/arquivos/pdf/Etica/7_lenzi.pdf〉. Acesso em: 02/09/2019.

MEDEIROS, Marcelo. Medidas de desigualdade e pobreza. Brasília: Editora Universidade de Brasília, 2012, disponível em:

https://econpolrg.files.wordpress.com/2013/05/medeiros_2012_medidas_de_desigualdade_e_ pobreza.pdf. Acesso em: 02/09/2019.

MDS. Área de imprensa. Disponível em http://mds.gov.br/area-de-

imprensa/noticias/2019/abril/bolsa-familia-repassa-r-2-6-bilhoes-a-beneficiarios-em-abril.

Acesso em: 02/09/2019.

MDS. Relatório. Disponível em

http://aplicacoes.mds.gov.br/sagi/RIv3/geral/relatorio_form.php?p_ibge=\&area=0\&ano_pesq uisa $=\&$ mes_pesquisa $=\&$ saida $=$ pdf $\&$ relatorio $=153 \& \mathrm{~ms}=623,460,587,589,450,448$. Acesso em: 02/09/2019. 
MDS. Relatório resumido bolsa família. Disponível em https://aplicacoes.mds.gov.br/sagirmps/bolsafamilia/relatorio-resumido-estadual.html. Acesso em: 02/09/2019.

NEVES, Marcelo. A força simbólica dos Direitos Humanos. Artigo publicado na Revista Eletrônica De Direito do Estado, n 4, outubro/novembro/dezembro de 2005, Salvador/BA.

ORGANIZAÇÃO DAS NAÇÕES UNIDAS. Agenda 2030: disponível em https://nacoesunidas.org/wp-content/uploads/2015/10/agenda2030-pt-br.pdf. Acesso em: 02/09/2019.

PLANALTO. Constituição Federal. Disponível em http://www.planalto.gov.br/ccivil_03/constituicao/ConstituicaoCompilado.htm. Acesso em: 02/09/2019.

PLANALTO. Lei Orgânica da Assistência Social. Disponível em http://www.planalto.gov.br/ccivil_03/LEIS/L8742compilado.htm. Acesso em: 02/09/2019.

REGO, Walquiria Leão e PINZANI, Alessandro. Vozes do Bolsa Família: autonomia, dinheiro e cidadania. Edição revista e ampliada, $2^{\text {a }}$ ed., São Paulo: Editora Unesp, 2014.

SANTOS, Boaventura de Sousa. Direitos humanos, democracia e desenvolvimento (p. 42). Marilena Chaui. São Paulo: Cortez, 2013

SEN, Amartya. Desenvolvimento Como Liberdade. Tradução Laura Teixeira Motta; revisão técnica Ricardo Doninelli Mendes. $4^{\text {a }}$ Reimpressão, São Paulo: Companhia das Letras, 2010.

SOUZA, Jessé. A elite do atraso: da escravidão à Lava Jato. Rio de Janeiro: Leya, 2017.

WORLD BANK. Atlas of Sustainable Development Goals 2017: From World Development Indicators. Washington, 2017. Disponível em: https://openknowledge.worldbank.org/handle/10986/26306>. Acesso em: 02/09/2019.

ZANIRATO, Sílvia Helena; ROTONDARO, Tatiana. Consumo, um dos dilemas da sustentabilidade. Estudos Avançados, São Paulo, v. 30, n. 88, p. 77-92, set./dez. 2016 Recebido: 21 de Novembro de 2017; Revisado: 23 de Abril de 2018; Aceito: 23 de Abril de 2018 